\title{
Water vapor retrieval from OMI visible spectra
}

\author{
H. Wang ${ }^{1}$, X. Liu ${ }^{1}$, K. Chance ${ }^{1}$, G. González Abad ${ }^{1}$, and C. Chan Miller ${ }^{2}$ \\ ${ }^{1}$ Harvard-Smithsonian Center for Astrophysics, Cambridge, MA 02138, USA \\ ${ }^{2}$ Department of Earth and Planetary Sciences, Harvard University, Cambridge, MA 02138, USA
}

Correspondence to: H. Wang (hwang @cfa.harvard.edu)

Received: 2 December 2013 - Published in Atmos. Meas. Tech. Discuss.: 22 January 2014

Revised: 21 April 2014 - Accepted: 23 May 2014 - Published: 30 June 2014

\begin{abstract}
There are distinct spectral features of water vapor in the wavelength range covered by the Ozone Monitoring Instrument (OMI) visible channel. Although these features are much weaker than those at longer wavelengths, they can be exploited to retrieve useful information about water vapor. They have an advantage in that their small optical depth leads to fairly simple interpretation as measurements of the total water vapor column density. We have used the Smithsonian Astrophysical Observatory (SAO) OMI operational retrieval algorithm to derive the slant column density (SCD) of water vapor using the 430-480 nm spectral region after extensive optimization. We convert from SCD to vertical column density (VCD) using the air mass factor (AMF), which is calculated using look-up tables of scattering weights and assimilated water vapor profiles. Our Level 2 product includes not only water vapor VCD but also the associated scattering weights and AMF. In the tropics, our standard water vapor product has a median SCD of $1.3 \times 10^{23}$ molecules $\mathrm{cm}^{-2}$ and a median relative uncertainty of about $11 \%$, about a factor of 2 better than that from a similar OMI algorithm that uses a narrower retrieval window. The corresponding median VCD is about $1.2 \times 10^{23}$ molecules $\mathrm{cm}^{-2}$. We have examined the sensitivities of SCD and AMF to various parameters and compared our results with those from the GlobVapour product, the Moderate Resolution Imaging Spectroradiometer (MODIS) and the Aerosol Robotic NETwork (AERONET).
\end{abstract}

\section{Introduction}

Water vapor is one of the key factors for weather. It is also the most abundant greenhouse gas in the atmosphere. It can provide strong feedback directly through amplification of global warming associated with other greenhouse gases and indirectly through formation of clouds. Water vapor participates in many photochemical reactions, such as the reaction with $\mathrm{O}\left({ }^{1} \mathrm{D}\right)$ to produce $\mathrm{OH}$ radicals, which control the oxidation capacity of the atmosphere. It is therefore also important for atmospheric chemistry. Unlike other long-lived greenhouse gases, the short-lived water vapor exhibits large spatial and temporal variability. Monitoring the distribution, variability and long-term changes in water vapor is critical for understanding the hydrological cycle, the earth radiative budget and climate change.

Water vapor has long been observed using a variety of platforms and methods, including measurements made from surface stations, balloons, aircrafts and satellites using in situ or remote sensing techniques. Satellite observations of water vapor have used microwave and radio wave (e.g., Advanced Microwave Sounding Unit (AMSU), Advanced Microwave Scanning Radiometer-Earth Observing System (AMSR-E), Special Sensor Microwave/Imager (SSM/I), Special Sensor Microwave Imager/Sounder (SSMI/S) (Ferraro et al., 2005; Boukabara et al., 2010), Global Navigation Satellite System (GNSS) (Lee et al., 2013)), thermal infrared (e.g., Moderate Resolution Imaging Spectrometer (MODIS) (King et al., 2003), Tropospheric Emission Spectrometer (TES) (Worden et al., 2012), Atmospheric Infrared Sounder (AIRS) (Aumann et al., 2003), Infrared Atmospheric Sounding Interferometer (IASI) (Schneider and Hase, 2011)), and nearinfrared and visible sensors (e.g., MODIS (King et al., 2003), Global Ozone Monitoring Experiment (GOME) (Noël et al., 2002; Wagner et al., 2003), GOME-2 (Grossi et al., 2014), Scanning Imaging Absorption spectrometer for Atmospheric CHartographY (SCIAMACHY) (Noël et al., 2004), Medium Resolution Imaging Spectrometer (MERIS) (Lindstrot et al., 2012)). 


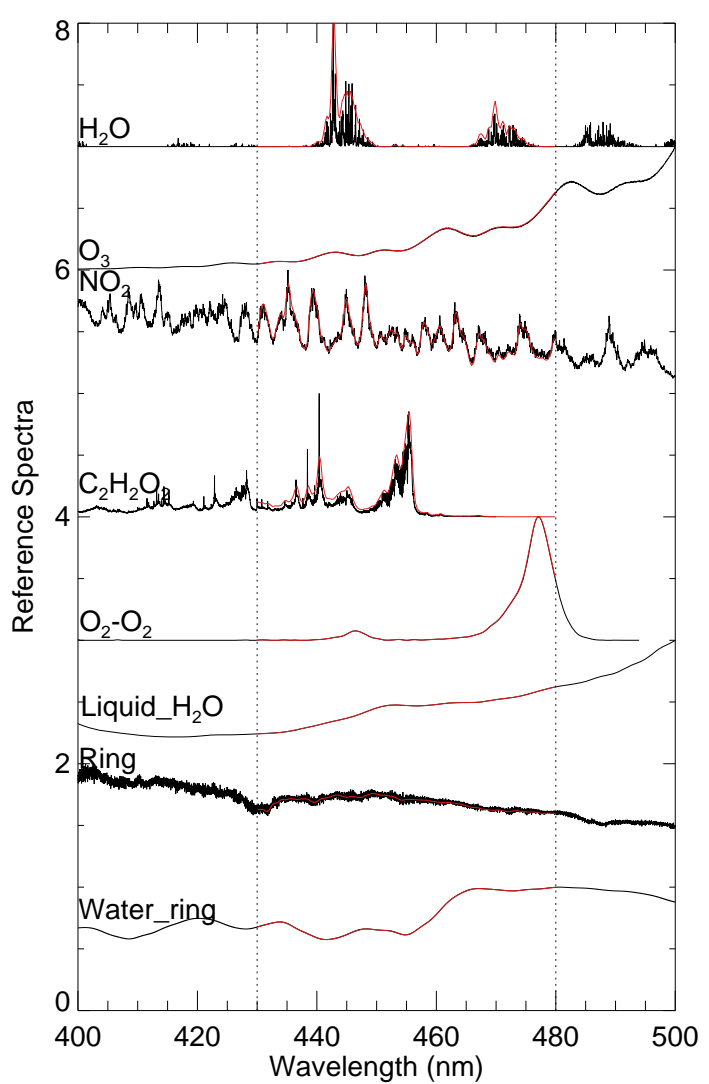

Figure 1. Reference spectra used in the standard operational water vapor retrieval. The spectra have been scaled for presentation purposes. The black lines are those listed in Table 1 . The red lines are the black lines convolved with the OMI slit function.

Wagner et al. (2013) demonstrated the feasibility of water vapor retrieval in the blue spectral range using GOME2 and Ozone Monitoring Instrument (OMI) measurements. They pointed out that the advantages of this spectral range include more consistent retrievals across the globe due to more uniform surface albedo, especially between land and ocean, increased sensitivity to near-surface layer due to higher surface albedo over the oceans than for longer wavelengths, less saturation of signal due to weaker water vapor absorption, applicability to sensors that do not cover longer wavelengths, and daily global coverage over a long period of time.

Wagner et al. (2013) derived OMI water vapor slant column densities (SCDs). We have independently derived OMI water vapor SCDs and converted them to vertical column densities (VCDs) using the Smithsonian Astrophysical Observatory (SAO) operational retrieval algorithm. In this paper, we will present our SCD retrievals, VCD calculations, sensitivity studies and initial validation results.

\section{Data processing}

\subsection{OMI instrument and OMI data}

OMI is a joint Dutch-Finnish instrument onboard the NASA EOS-Aura satellite, which was launched on 15 July 2004 into a sun-synchronous orbit with an ascending node Equator crossing time of around 13:45 LT and an orbital period of about $100 \mathrm{~min}$ (Schoeberl et al., 2006). It is a nadir-viewing push-broom ultraviolet/visible (UV/VIS) imaging spectrometer with three channels - the UV1 (264-311 nm), UV2 $(307-383 \mathrm{~nm})$ and VIS $(349-504 \mathrm{~nm})-$ at $0.42-0.63 \mathrm{~nm}$ spectral resolution (Levelt et al., 2006). For the visible channel, the $2600 \mathrm{~km}$ OMI cross-track swath usually provides a nominal spatial resolution between $13 \mathrm{~km} \times 24 \mathrm{~km}$ at nadir and $26 \mathrm{~km} \times 135 \mathrm{~km}$ at the edge. The entire globe is covered by $14-15$ orbits each day. Solar irradiance measurements are performed daily.

We use Version 3 Level 1B OMI visible spectra to derive water vapor SCD, and Version 3 Level 2 OMI cloud pressure and cloud fraction product (OMCLDO2) downloaded from disc.sci.gsfc.gov/Aura/data-holdings/OMI/ for air mass factor (AMF) calculation.

\subsection{Slant column retrieval}

\subsubsection{Standard retrieval}

We determine the slant column of water vapor by directly fitting the OMI spectra following the method described in Chance (1998). The method is also presented in detail in González Abad et al. (2014). In this paper, we only provide a brief description.

Wavelength calibration is performed using crosscorrelation through spectral shift (Caspar and Chance, 1997) with a high-resolution solar reference spectrum (Chance and Kurucz, 2010). To reduce noise, we use the leading principle component derived from OMI solar spectra as the measured solar spectrum. The slant column abundance that minimizes the difference between the measured and calculated radiance is retrieved using a non-linear least squares inversion method by Lindström and Wedin (1988). We use a spectral window from $430 \mathrm{~nm}$ to $480 \mathrm{~nm}$ for our standard water vapor retrieval as it leads to the smallest retrieval uncertainty (Sect. 2.2.2). A third-order polynomial is fitted for both the baseline and the scaling factor to account for broadband spectral features. Common mode and under-sampling spectra (Chance et al., 2005) are derived on-line and applied to the fitting. The retrieval takes into consideration water vapor, ozone, nitrogen dioxide, oxygen collision complex, liquid water, glyoxal, the ring effect (Chance and Spurr, 1997) and the liquid water ring effect. The molecular reference spectra used in our standard retrieval are listed in Table 1 and plotted in Fig. 1. There are distinct spectral signatures of these molecules in our retrieval window. The reference spectra 
are interpolated onto common calibrated radiance grid and convolved with pre-determined instrument slit function (Dirksen et al., 2006) during the fitting (Fig. 1). Ozone, nitrogen dioxide, water vapor and glyoxal are corrected for the solar $I_{0}$ effect (Aliwell et al., 2002).

Figure 2 shows our standard retrieval result for the SCD and the associated absolute and relative uncertainties for 14 July 2005 (orbits 5297-5311). As expected, the global pattern shows more water vapor in the Intertropical Convergence Zone (ITCZ) and mid-latitude weather systems. There are some stripes along the swaths (Veihelmann and Kleipool, 2006) as we have not applied our post-processing routine to remove them for this plot. The stripes are mainly caused by OMI systematic measurement errors and are common to most OMI Level 2 products. In the tropics $\left(30^{\circ} \mathrm{S}-30^{\circ} \mathrm{N}\right)$, the median of SCD is $1.32 \times 10^{23}$ molecules $\mathrm{cm}^{-2}$, the median of fitting uncertainty is $1.2 \times 10^{22}$ molecules $\mathrm{cm}^{-2}$, the median of relative uncertainty (fitting uncertainty/SCD) is $11 \%$ and the median of the fitting root mean square (rms) ratio to the radiance is $9.2 \times 10^{-4}$. Areas with larger SCD generally have smaller uncertainties.

The $25 \%$ and $75 \%$ percentiles of our fitting uncertainties in the tropics are $1.0 \times 10^{22}$ and $1.7 \times 10^{22}$ molecules $\mathrm{cm}^{-2}$, respectively. In comparison, using a shorter retrieval window of 430-450 nm, Wagner et al. (2013) obtained typical SCD uncertainties of $3-5 \times 10^{22}$ molecules $\mathrm{cm}^{-2}$ for OMI and 1$2.5 \times 10^{22}$ molecules $\mathrm{cm}^{-2}$ for GOME-2. The uncertainty of our standard water vapor SCD is therefore smaller than the Wagner et al. (2013) OMI result and similar to the Wagner et al. (2013) GOME-2 result.

Figure 3 shows examples of our spectral fitting for two pixels from orbit 5306 in July 2005. The left column is for a pixel at $1.75^{\circ} \mathrm{S}$ and $34.6^{\circ} \mathrm{W}$ in the Atlantic Ocean, and the right column is for a pixel at $47.75^{\circ} \mathrm{N}$ and $53.4^{\circ} \mathrm{W}$ at the Atlantic coast of North America. The retrieved water vapor SCDs are $(1.23 \times 0.12) \times 10^{23}$ and $(1.75 \times 0.07) \times 10^{23}$ molecules $\mathrm{cm}^{-2}$, respectively. The corresponding rms values are $1.1 \times 10^{-3}$ and $4.0 \times 10^{-4}$, respectively. The panels in the top row show that the fitted spectra (red) closely track the measured spectra (black). The panels in the second row show that the fitting residuals appear random except for two minor noise spikes in the righthand spectrum. The next four rows show the reference spectra of important molecules (water vapor, liquid water, nitrogen dioxide and ozone) scaled by their corresponding fitted SCDs (black) and added to the fitting residuals in the second row (red). In both cases, the water vapor spectral signature within the fitting window is stronger than the fitting residuals. Consistent with the expectation that there is less liquid water, more $\mathrm{NO}_{2}$ and more $\mathrm{O}_{3}$ in the mid-latitude coastal area than in the tropical open ocean, the right panels show that the liquid water signal is weaker and the $\mathrm{NO}_{2}$ and $\mathrm{O}_{3}$ signals are stronger than the residual, while the left panels show the opposite.
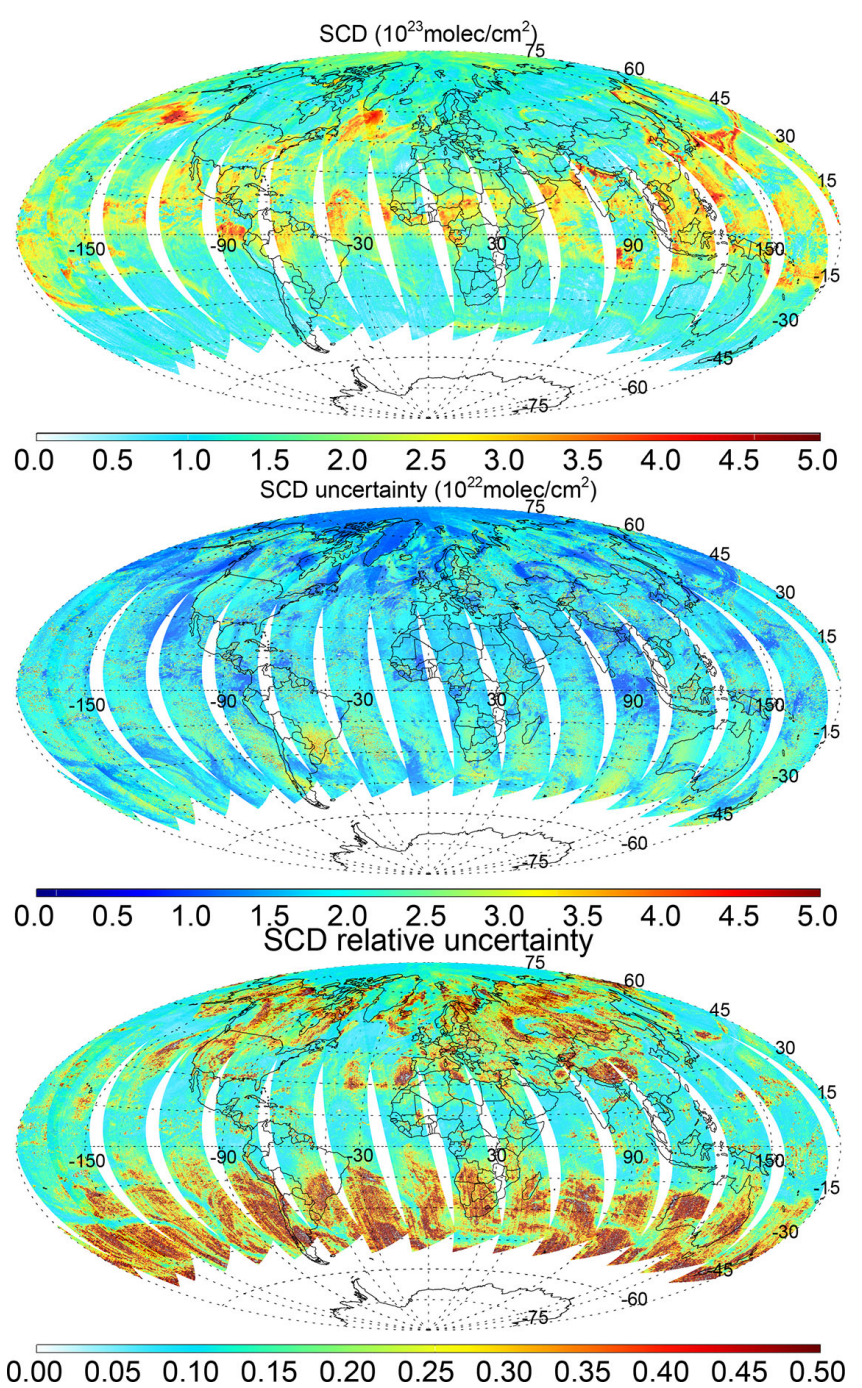

Figure 2. OMI water vapor (top) SCD, (middle) SCD uncertainty and (bottom) SCD relative uncertainty for 14 July 2005 from the standard retrieval.

\subsubsection{Sensitivity studies}

We have investigated the sensitivity of OMI water vapor SCD with respect to the retrieval window. Selected examples are listed in Table 2. We vary the retrieval window while keeping everything else the same. All the retrieval windows in Table 2 include the water vapor feature at about $442 \mathrm{~nm}$. The $438-478 \mathrm{~nm}$ and the standard $430-480 \mathrm{~nm}$ window also include the weaker water vapor feature at about $470 \mathrm{~nm}$, and the longest window (430-495 nm) includes an additional weaker feature at about $485 \mathrm{~nm}$. The median SCDs and uncertainties within $30^{\circ} \mathrm{N}-30^{\circ} \mathrm{S}$ for 14 July 2005 are listed in Table 2 . The standard window leads to the smallest uncertainty $\left(1.2 \times 10^{22}\right.$ molecules $\left.\mathrm{cm}^{-2}\right)$. The uncertainties for the $20 \mathrm{~nm}$ and $30 \mathrm{~nm}$ windows are about $100 \%$ and $67 \%$ larger, respectively. The uncertainty for the $65 \mathrm{~nm}$ window is about 
Table 1. Reference spectrum used in standard retrieval.

\begin{tabular}{lll}
\hline Molecule & $T(\mathrm{~K})$ & Reference \\
\hline Water vapor $\left(\mathrm{H}_{2} \mathrm{O}\right)$ & 280 & Rothman et al. (2009) \\
Ozone $\left(\mathrm{O}_{3}\right)$ & 228 & Brion et al. (1993) \\
Nitrogen dioxide $\left(\mathrm{NO}_{2}\right)$ & 220 & Vandaele et al. (1998) \\
Oxygen collision complex $\left(\mathrm{O}_{2}-\mathrm{O}_{2}\right)$ & 294 & http://spectrolab.aeronomie.be/o2.htm \\
Pure liquid water $\left(\mathrm{H}_{2} \mathrm{O}\right)$ & - & Pope and Fry (1997) \\
Glyoxal $\left(\mathrm{C}_{2} \mathrm{H}_{2} \mathrm{O}_{2}\right)$ & 296 & Volkamer et al. (2005) \\
Ring and water ring & - & Chance and Spurr (1997) \\
\hline
\end{tabular}
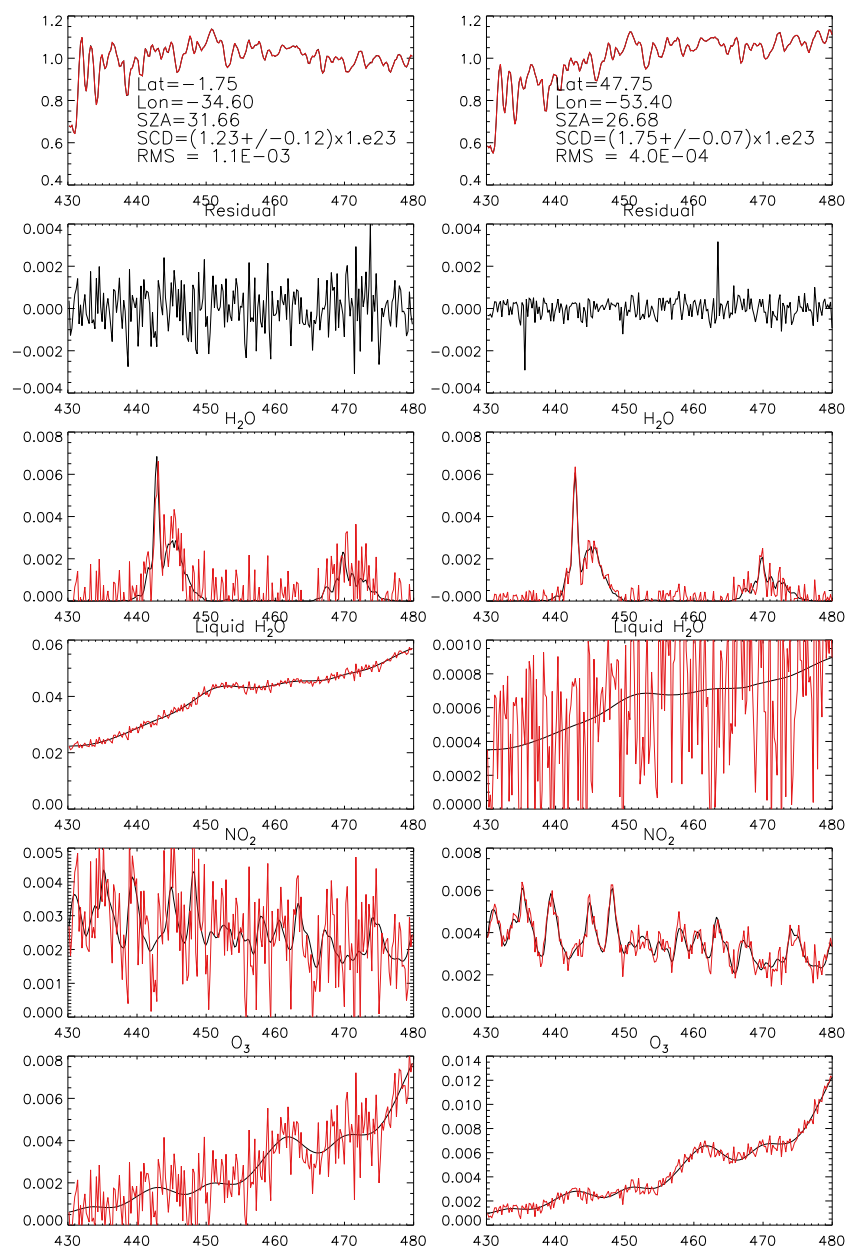

Figure 3. Spectral fitting results for (left) a pixel in the Atlantic Ocean and (right) a pixel near the Atlantic coast of North America. The first row shows the fitted (red) and measured (black) spectra. The second row shows the fitting residuals. The third to sixth rows show the reference spectra of $\mathrm{H}_{2} \mathrm{O}$, liquid water, $\mathrm{NO}_{2}$ and $\mathrm{O}_{3}$ scaled by the fitted slant columns (black) and added to the fitting residuals (red).
$25 \%$ larger. The median SCD decreases from $1.47 \times 10^{23}$ to $1.23 \times 10^{23}$ molecules $\mathrm{cm}^{-2}$ as the retrieval window length increases.

We have performed additional sensitivity studies, shown in Table 3, by excluding the interfering molecules, changing the reference spectra and changing the order of closure polynomials. In these experiments, everything else is kept the same as in the standard retrieval. In Table 3, we list the median statistics and the number of negative retrievals for water vapor between $30^{\circ} \mathrm{S}$ and $30^{\circ} \mathrm{N}$ for 14 July 2005 .

Exclusion of $\mathrm{O}_{3}, \mathrm{O}_{2}-\mathrm{O}_{2}, \mathrm{NO}_{2}$ or liquid water leads to significant (10-30\%) reduction of the retrieved water vapor SCDs and large increase of the number of negative retrievals, though the fitting uncertainties and rms remain at the same level. The most severe change is associated with liquid water, followed by $\mathrm{NO}_{2}, \mathrm{O}_{2}-\mathrm{O}_{2}$ and $\mathrm{O}_{3}$. Exclusion of $\mathrm{C}_{2} \mathrm{H}_{2} \mathrm{O}_{2}$ leads to only about $1 \%$ increase of water vapor SCD. Without liquid water, the medium water vapor SCD decreases by about $32 \%$ from $1.32 \times 10^{23}$ to $0.90 \times 10^{23}$ molecules $\mathrm{cm}^{-2}$, and the number of negative retrievals increases from 1935 to 50216 . It should be noted that such a strong sensitivity to liquid water is for the standard long retrieval window of $430-480 \mathrm{~nm}$. For the shorter window of $432-462 \mathrm{~nm}$, the difference in the median SCD with and without liquid water is only about $4 \%$, which is substantially smaller than the median relative uncertainty.

As a by-product of our standard water vapor retrieval, the top panel of Fig. 4 shows the retrieved liquid water on 14 July 2005. Although the retrieval is not optimized for liquid water, areas in the oceans, seas, gulfs and so on are highlighted. Not all liquid water bodies are highlighted to the same extent. Comparison between the top and middle panels of Fig. 4 shows that some liquid water surfaces are shielded by clouds. The bottom panel of Fig. 4 shows the retrieved water vapor SCD without considering liquid water. Compared to the standard retrieval shown in the top panel of Fig. 2, the SCDs here are apparently smaller, especially over the areas with liquid water where many negative values (plotted as blanks) are retrieved.

To further investigate the influence of liquid water, we examine the common mode in Fig. 5 for Orbit 5311, which is dominated by ocean and Orbit 5304, which is dominated by 
Table 2. Sensitivity to retrieval window.

\begin{tabular}{|c|c|c|c|c|}
\hline $\begin{array}{l}\text { Window } \\
\text { length (nm) }\end{array}$ & $\begin{array}{l}\text { Retrieval } \\
\text { window (nm) }\end{array}$ & $\begin{array}{l}\text { Median SCD } \\
\left(\text { molecule } \mathrm{cm}^{-2}\right)\end{array}$ & $\begin{array}{l}\text { Median uncertainty } \\
\left(\text { molecule } \mathrm{cm}^{-2} \text { ) }\right.\end{array}$ & $\begin{array}{l}\text { Median relative } \\
\text { uncertainty }\end{array}$ \\
\hline 20 & {$[435,455]$} & $1.47 \times 10^{23}$ & $2.4 \times 10^{22}$ & 0.19 \\
\hline 30 & {$[432,462]$} & $1.43 \times 10^{23}$ & $2.0 \times 10^{22}$ & 0.17 \\
\hline 40 & {$[438,478]$} & $1.35 \times 10^{23}$ & $1.6 \times 10^{22}$ & 0.15 \\
\hline 50 (standard) & {$[430,480]$} & $1.32 \times 10^{23}$ & $1.2 \times 10^{22}$ & 0.11 \\
\hline 65 & {$[430,495]$} & $1.23 \times 10^{23}$ & $1.5 \times 10^{22}$ & 0.12 \\
\hline
\end{tabular}

Table 3. Miscellaneous sensitivity studies.

\begin{tabular}{|c|c|c|c|c|}
\hline Description & $\begin{array}{l}\text { Median SCD } \\
\left(\text { molecule } \mathrm{cm}^{-2}\right)\end{array}$ & $\begin{array}{l}\text { Median uncertainty } \\
\left(\text { molecule } \mathrm{cm}^{-2}\right)\end{array}$ & $\begin{array}{l}\text { Median } \\
\text { rms }\end{array}$ & $\begin{array}{l}\text { Number of } \\
\text { negatives }\end{array}$ \\
\hline Standard & $1.32 \times 10^{23}$ & $1.2 \times 10^{22}$ & $9.2 \times 10^{-4}$ & 1935 \\
\hline Without $\mathrm{O}_{3}$ & $1.19 \times 10^{23}$ & $1.2 \times 10^{22}$ & $9.3 \times 10^{-4}$ & 7234 \\
\hline Without $\mathrm{O}_{2}-\mathrm{O}_{2}$ & $1.18 \times 10^{23}$ & $1.3 \times 10^{22}$ & $9.9 \times 10^{-4}$ & 5076 \\
\hline Without $\mathrm{NO}_{2}$ & $1.05 \times 10^{23}$ & $1.2 \times 10^{22}$ & $9.3 \times 10^{-4}$ & 15666 \\
\hline Without liquid water & $0.90 \times 10^{23}$ & $1.1 \times 10^{22}$ & $9.5 \times 10^{-4}$ & 50216 \\
\hline Without $\mathrm{C}_{2} \mathrm{H}_{2} \mathrm{O}_{2}$ & $1.34 \times 10^{23}$ & $1.2 \times 10^{22}$ & $9.2 \times 10^{-4}$ & 1780 \\
\hline Switch to fifth-order polynomial & $1.32 \times 10^{23}$ & $1.3 \times 10^{22}$ & $9.0 \times 10^{-4}$ & 2262 \\
\hline Switch reference $\mathrm{H}_{2} \mathrm{O}$ to $0.7 \mathrm{~atm}$ and $265 \mathrm{~K}$ & $1.29 \times 10^{23}$ & $1.2 \times 10^{22}$ & $9.2 \times 10^{-4}$ & 1992 \\
\hline Switch reference $\mathrm{H}_{2} \mathrm{O}$ to $1.0 \mathrm{~atm}$ and $288 \mathrm{~K}$ & $1.34 \times 10^{23}$ & $1.2 \times 10^{22}$ & $9.2 \times 10^{-4}$ & 1918 \\
\hline Switch to Rothman et al. (2013) HITRAN 2012 water vapor & $1.24 \times 10^{23}$ & $1.2 \times 10^{22}$ & $9.2 \times 10^{-4}$ & 1816 \\
\hline Switch to Thalman and Volkamer (2013) $\mathrm{O}_{2}-\mathrm{O}_{2}$ & $1.31 \times 10^{23}$ & $1.2 \times 10^{22}$ & $9.2 \times 10^{-4}$ & 2185 \\
\hline
\end{tabular}

land. The common mode for each orbit is derived from the average of the fitting residuals. The fitting program then uses the derived common mode as a reference spectrum for the final retrieval. Since common mode is fitted, the change in the median fitting rms in Table 3 is small. Further exclusion of the common mode from the retrieval without liquid water will lead to an increase of the median rms for the day from $9.5 \times 10^{-4}$ to $1.13 \times 10^{-3}$. The common modes for the retrieval without liquid water are shown in the second row. There are apparent spectral structures in the common mode for the ocean-dominated Orbit 5311. In comparison, the common appears more random for the land-dominated Orbit 5304. The median rms in this case is $9.7 \times 10^{-4}$ for Orbit 5311 and $8.5 \times 10^{-4}$ for Orbit 5304. When liquid water is included in the retrieval, the bottom row shows that the spectral structures of the common mode for Orbit 5311 are reduced while those for Orbit 5304 are little affected. The median rms for the standard retrieval is $9.4 \times 10^{-4}$ for Orbit 5311 and $8.4 \times 10^{-4}$ for Orbit 5304. The remaining structures in the common mode of the standard retrieval over the ocean probably suggest errors in the liquid water reference spectrum. This will be investigated further in the future.

After obtaining new reference spectra for water vapor and oxygen collision complex, we have tested the sensitivity of our standard retrieval with respect to them. Switching from HITRAN 2008 (Rothman et al., 2009) to HITRAN 2012
(Rothman et al., 2013) water vapor reference makes the median SCD about $6 \%$ lower than that of the standard retrieval. In comparison, the median relative uncertainty of the standard retrieval is about $11 \%$. Switching to the Thalman and Volkamer (2013) $\mathrm{O}_{2}-\mathrm{O}_{2}$ reference spectrum gives almost the same result as the standard retrieval, so does switching from a third-order to a fifth-order closure polynomial for the baseline and scaling factor. The median of SCD retrieved using water vapor reference spectrum at $0.7 \mathrm{~atm}$ and $265 \mathrm{~K}$ is about $2 \%$ lower than the standard result, and that using water vapor reference at $1.0 \mathrm{~atm}$ and $288 \mathrm{~K}$ is about $2 \%$ higher. Due to the small changes in the SCD statistics, we have not updated the standard retrieval with the new reference spectra.

\section{Vertical column calculation}

\subsection{AMF calculation}

To derive the VCD, we divide SCD by AMF, i.e., $\mathrm{VCD}=\mathrm{SCD} / \mathrm{AMF}$. The AMF can be expressed for optically thin absorption as the vertical integral of the product of the scattering weight and the shape factor, where the scattering weight accounts for the sensitivity of the measurement to water vapor as a function of altitude and the shape factor accounts for the normalized vertical profile of water vapor (Palmer et al., 2001). Averaging kernels can be derived as 


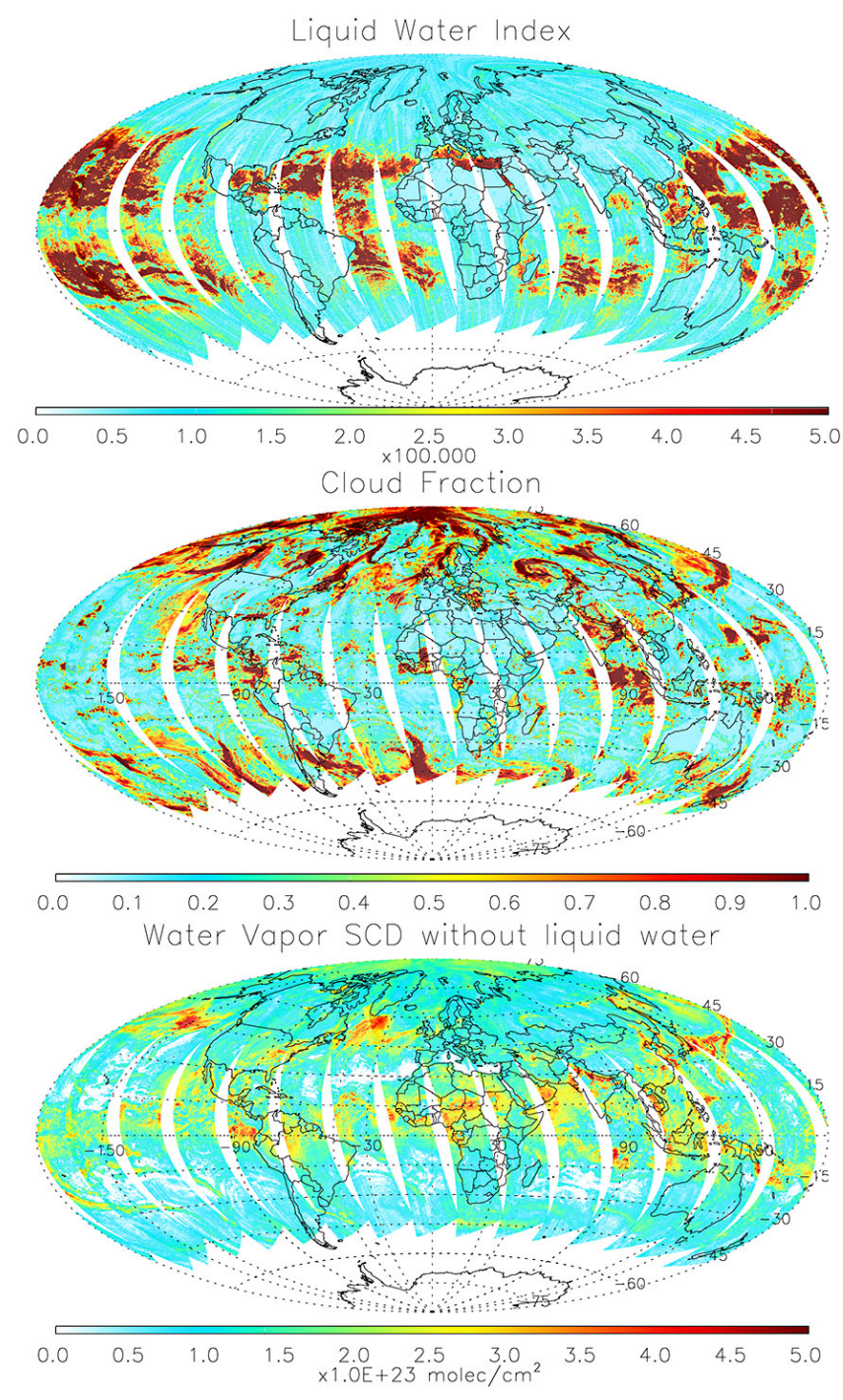

Figure 4. The top panel shows the liquid water index from a byproduct of our standard water vapor retrieval. The middle panel shows the cloud fraction from the OMCLDO2 product. The bottom panel shows the water vapor SCD from a sensitivity study where liquid water is excluded from the water vapor retrieval. All results are for 14 July 2005.

the ratio of the scattering weights to the AMFs (Eskes and Boersma, 2003). Our Level 2 product provides VCDs with the scattering weights and AMFs for comparison with or assimilation into models. More details about the AMF calculation for our operational retrieval algorithm can be found in González Abad et al. (2014).

The a priori vertical profiles of water vapor for the shape factor are from the monthly mean early afternoon GEOS-5 data assimilation product. They are generated at the Global Modeling and Assimilation Office (GMAO) and re-gridded to $2^{\circ}$ latitude $\times 2.5^{\circ}$ longitude $\times 47$ layer resolution (for GEOS-Chem simulations). We use the monthly mean profiles in our operational retrieval to avoid the need
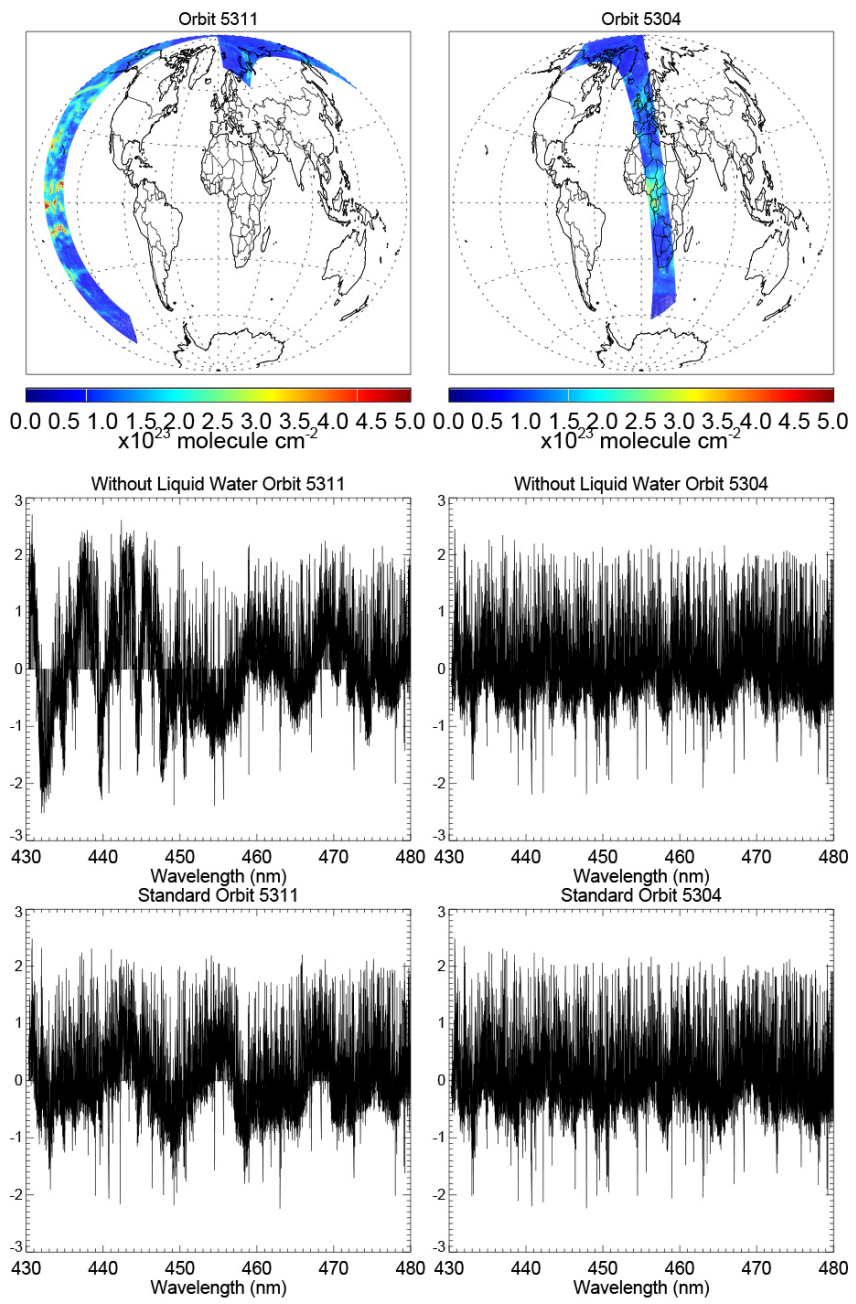

Figure 5. The top row shows the OMI VCDs for Orbit 5311, which is mostly over the ocean, and for Orbit 5304, which is mostly over the land. The middle row shows the common modes for the two orbits when liquid water is excluded from the standard retrieval. The bottom row shows the common modes for the two orbits from the standard retrieval, which includes liquid water.

of obtaining near-real-time water vapor assimilation product. The retrieved water vapor VCDs can be easily adjusted using the provided scattering weights when water vapor profiles of higher spatial and temporal resolution are used. As a representative example, the left panel of Fig. 6 shows the monthly and zonal mean water vapor profile at $10^{\circ} \mathrm{N}$ in July 2007. It can be seen that water vapor is highly concentrated near the surface where the $e$ folding scale height is approximately $4 \mathrm{~km}$.

The scattering weights are calculated using the VLIDORT radiative transfer model (Spurr, 2006). To speed up the computation, we prepare a scattering weight look-up table based on the surface albedo, observational geometry, surface height and cloud height. For partly cloudy scenes, the scattering weight is approximated as the radiative cloud fraction $(\phi)$ 

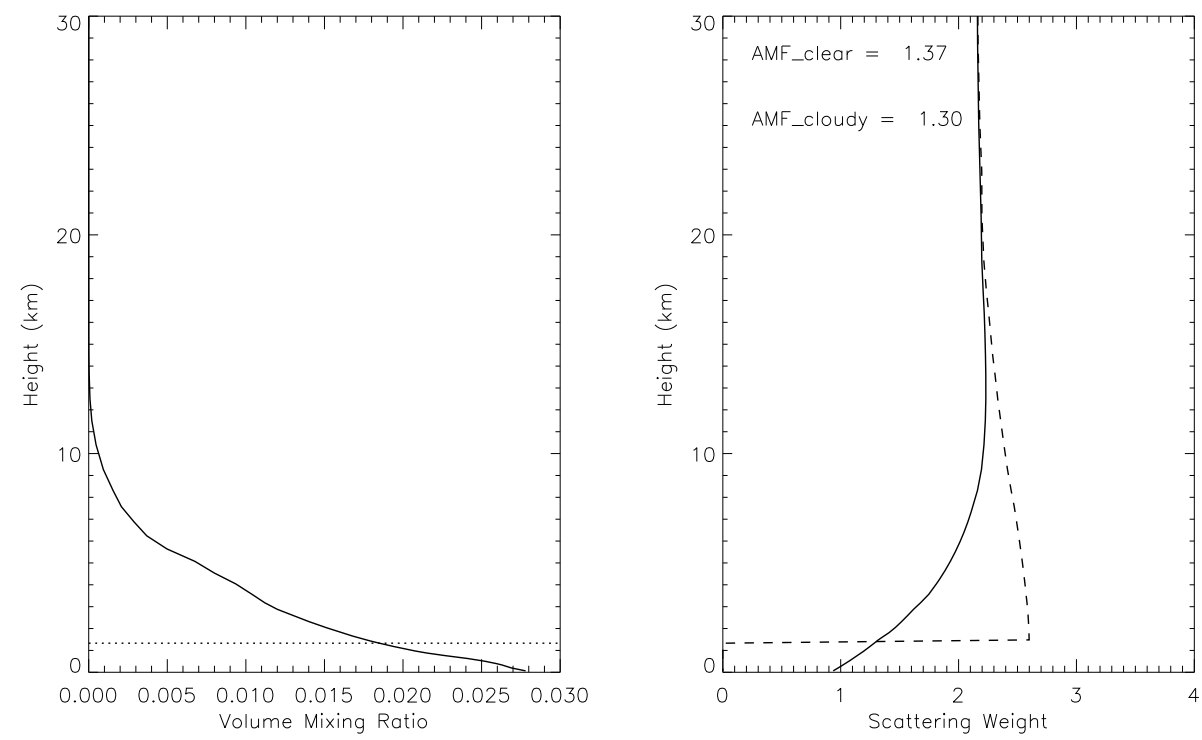

Figure 6. The left panel shows a representative water vapor vertical profile in the tropics. The dotted line indicates the height of the $800 \mathrm{mb}$ level. The right panel shows the scattering weight for a (solid line) clear and a (dashed) cloudy atmosphere where the modeled Lambertian cloud surface is at the $800 \mathrm{mb}$ level.

weighted average of the clear and cloudy part (Martin et al., 2002). The radiative cloud fraction is calculated as the cloud fraction $(f)$ weighted by the radiance intensity of the clear $\left(I_{\text {clear }}\right)$ and cloudy $\left(I_{\text {cloud }}\right)$ scenes $\left(\phi=\frac{f \cdot I_{\text {cloud }}}{(1-f) \cdot I_{\text {clear }}+f \cdot I_{\text {cloud }}}\right.$, González Abad et al., 2014).

We use the effective cloud fraction and cloud pressure from the Version 3 Level 2 OMICLDO2 product, which is derived using the $\mathrm{O}_{2}-\mathrm{O}_{2}$ absorption band at about $477 \mathrm{~nm}$ (Stammes and Noordhoek, 2002; Acaretta et al., 2004; Stammes et al., 2008). In the cloud algorithm, a cloud is represented by a Lambertian reflector with an albedo of 0.8 . Consequently, a thin cloud that fully covers an OMI pixel is represented by a small effective cloud fraction. In addition, the retrieved cloud height is mostly inside the cloud. To keep consistency with the OMCLDO2 product, we also model a cloud as a Lambertian surface with an albedo of 0.8 .

As an example, the right panel of Fig. 6 shows the scattering weight for a clear (cloud fraction $=0$, solid line) and a cloudy (cloud fraction $=1$ at $800 \mathrm{mb}$, which is at a height of about $1.5 \mathrm{~km}$, dashed line) scene under typical conditions. For a clear atmosphere, the scattering weight decreases toward the surface where most of the water vapor resides. For a cloudy atmosphere, the scattering weight shows a jump at the cloud level where the sensitivity immediately above increases due to enhanced multiple scattering and that below drops to zero due to cloud shielding.

\subsection{AMF sensitivity}

Since errors in AMF affect the quality of VCD, we investigate the sensitivity of the AMF with respect to wavelength, solar zenith angle, surface albedo and cloud pressure in Fig. 7. As a reference, we use a wavelength of $442 \mathrm{~nm}$, surface albedo of 0.05 , viewing zenith angle of $0^{\circ}$, solar zenith angle of $30^{\circ}$ and surface height of $0 \mathrm{~km}$. The top three panels of Fig. 7 correspond to a clear atmosphere, and the bottom panel corresponds to a cloudy atmosphere with cloud fraction of 1 . We vary the parameters of interest one at a time to examine the AMF sensitivity.

The top panel of Fig. 7 shows that AMF is almost insensitive to wavelength. There is only about $1 \%$ change over the $430-480 \mathrm{~nm}$ range. To speed up computation in our operational retrieval, we use the AMF at $442 \mathrm{~nm}$, which is within the strongest water vapor band in the $430-480 \mathrm{~nm}$ retrieval window. The second panel of Fig. 7 shows that the AMF increases from 1.25 to 1.85 as the solar zenith angle increases from $0^{\circ}$ to $80^{\circ}$. Since the viewing geometries of satellite observations are precisely determined, errors due to this source can be neglected.

The third panel of Fig. 7 shows that the AMF is quite sensitive to surface albedo. In the blue wavelength region, surface albedo is usually in the range of 0.05 0.15 (Koelemeijer et al., 2003), which corresponds to the steepest slope of the AMF versus albedo curve. For the standard retrieval, we use an updated version of the OMI Lambert equivalent surface reflectance climatology - OMLER $\left(0.5^{\circ} \times 0.5^{\circ}\right.$, http://disc.sci.gsfc.nasa. gov/Aura/data-holdings/OMI/omler_v003.shtml) (Kleipool et al., 2008). Due to the spectral dependence, spatial heterogeneity and temporal variability, surface albedo estimates can have significant error. Kleipool et al. (2008) showed that the estimated absolute uncertainties were 0.01-0.02 in the blue spectral rage. Figure 7 suggests that an increase of surface albedo by 0.02 can result in an increase of AMF by about 

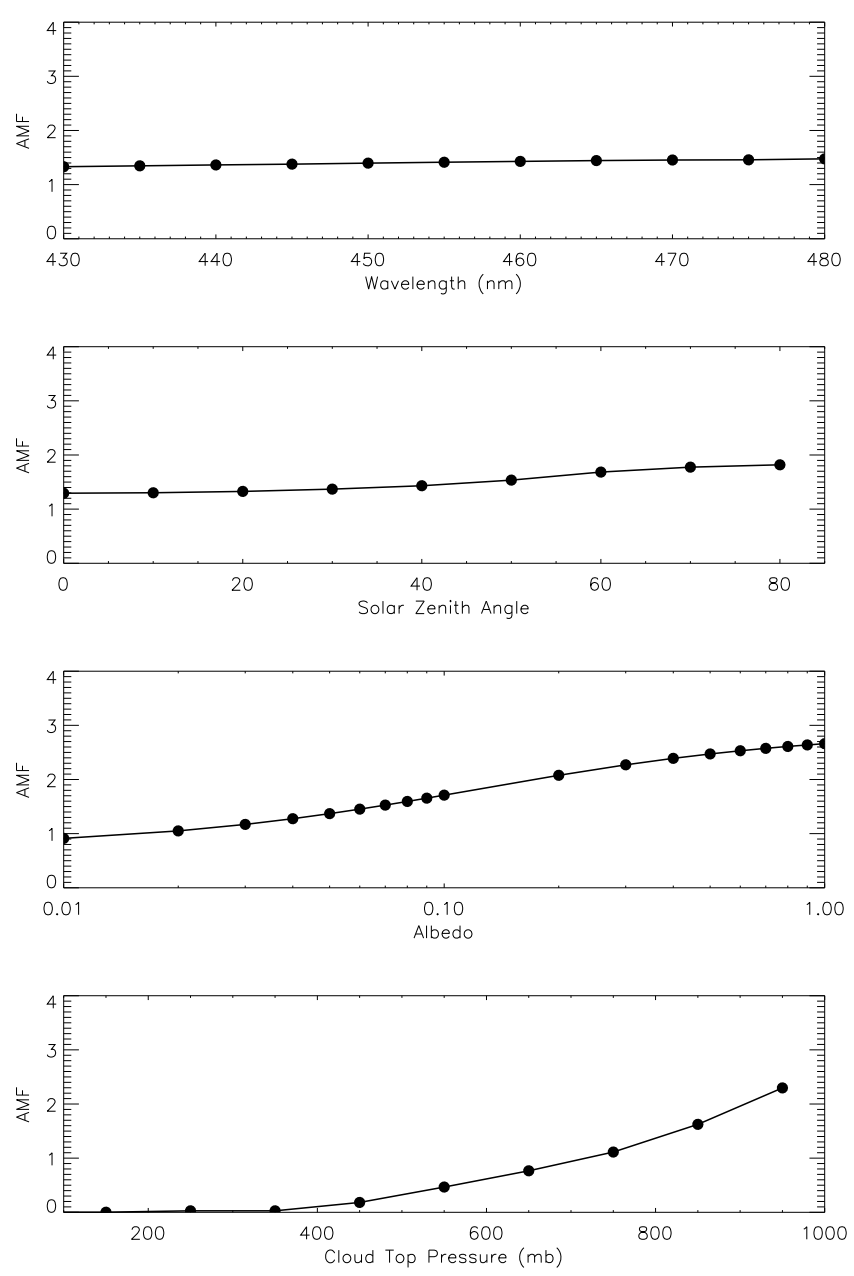

Figure 7. The variation of the AMF with respect to the wavelength, solar zenith angle, surface albedo and cloud height.

$9 \%$. We will investigate the effect of using surface albedo database of higher spatial and temporal resolution (e.g., from MODIS) in the future.

Cloud is another factor that strongly affects AMF and VCD. The right panel of Fig. 6 shows that water vapor below the cloud is shielded from the view. As a result, AMF increases with increasing cloud top pressure (bottom panel of Fig. 7). The cloud product we use (OMCLDO2) is derived from $\mathrm{O}_{2}-\mathrm{O}_{2}$ absorption band at about $477 \mathrm{~nm}$. An alternative cloud product (OMCLDRR) is derived from rotational Raman scattering at about $350 \mathrm{~nm}$ (Joiner and Vassilkov, 2006). In both cases, the derived cloud pressure is different from that at the physical cloud top (Stammes et al., 2008; Vasilkov et al., 2008). A comparison by Sneep et al. (2008) shows that the differences in cloud pressure between them average between 2 and $45 \mathrm{mb}$ with an rms difference of 65 to $93 \mathrm{mb}$. Figure 7 shows that the AMF increases from 1.6 to 2.0 as the cloud pressure increases from $850 \mathrm{mb}$ to $900 \mathrm{mb}$.
Aerosols influence atmospheric scattering and therefore AMF. There are different types of aerosols, and their distributions are highly variable. This can potentially introduce significant error in AMF estimation. However, since the cloud product that we use does not consider aerosols, any effect associated with aerosols is aliased into the cloud information. To be consistent, we do not consider aerosols in our radiative transfer calculation in this paper. In the future, we will perform additional studies to better understand the influence of aerosols on our retrieval.

\section{Validation}

In this section, we present our initial data validation results. A comprehensive data validation will be performed later. In this paper, we compare our VCDs with the MODIS near-IR data, the GlobVapour MERIS+SSM/I combined data and the AERONET ground-based measurements.

The MODIS near-IR total precipitable water product (Gao and Kaufman, 2003) is derived using the ratios of water vapor absorbing channels $(0.905,0.936$ and $0.94 \mu \mathrm{m})$ and atmospheric window channels $(0.865$ and $1.24 \mu \mathrm{m})$ in the near-IR. The retrieval algorithm relies on observations of water vapor attenuation of reflected sunlight. Therefore, results only exist for reflective surfaces in the near-IR. The errors are typically about 5-10\%, with greater errors over dark surfaces and under hazy conditions. Consequently, the data quality is generally better over the land than over the ocean. In this paper, we use the Level 3 monthly $1^{\circ} \times 1^{\circ}$ data from the Aqua platform (MYD08_M3) (ladsweb.nascom.nasa.gov/data/). Aqua is about 15 min ahead of OMI's host satellite Aura in the "Atrain" constellation. Wang et al. (2007) found significant diurnal cycles of precipitable water that vary with region and season. The closeness in local time of observation between $\mathrm{OMI}$ and MODIS is nice for comparison.

The top panels of Fig. 8 show our results of the monthly mean $1^{\circ} \times 1^{\circ}$ water vapor VCDs derived from the standard retrieval for January and July 2006. For easy comparison with MODIS, we have converted the VCDs from molecule $\mathrm{cm}^{-2}$ to (precipitable) $\mathrm{cm}$ using a multiplication factor of $2.98904 \times 10^{-23}$ and indicated both units on the color bars of the figure. The gridded OMI data are calculated using the weighted average of the retrieved VCDs whose cloud fractions are less than 0.25 . The weight is assigned according to both the area of the ground pixel within the grid box and the fitting uncertainty. The number of data points for a grid box ranges from 0 to about 900 with a median of about 100. The stripes in daily maps (Fig. 2) are averaged out here. The corresponding MODIS results are shown in the second row of Fig. 8. There are lots of missing data (blank areas) in the MODIS maps mainly due to the low near-IR surface reflectivity over the ocean (except under sun glint condition). Both OMI and MODIS show the seasonal shift of the Intertropical Convergence Zone (ITCZ). The OMI-MODIS 


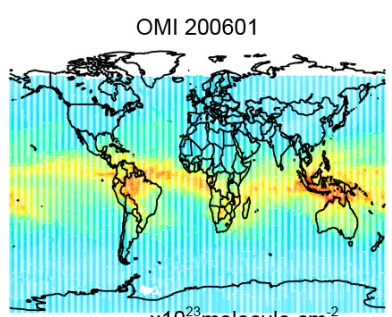

$-0.30 .00 .30 .71 .01 .31 .72023273 .0-0.300030 .71 .01 .31 .72023273 .0$ $-1.00 .01 .02 .03 .04 .05 .06 .07 .08 .09 .0-1.00 .01 .02 .03 .04 .05 .06 .07 .08 .09 .0$

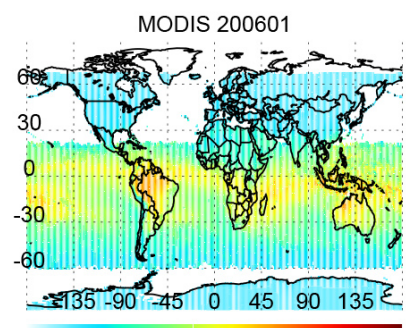

$-1.00 .01 .02 .03 .04 .05 .06 .07 .08 .09 .0-1.00 .01 .02 .03 .04 .05 .06 .07 .08 .09 .0$

OMI-MODIS 200601

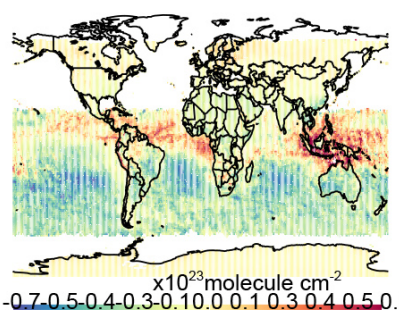

$-2.0-1.6-1.2-0.8-0.40 .00 .40 .81 .21 .62 .0$
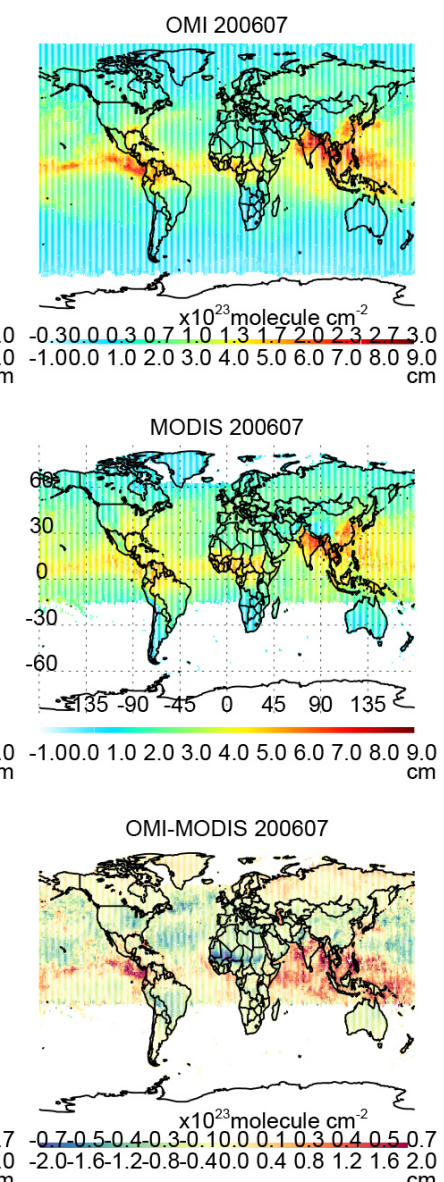

Figure 8. The first row shows the monthly mean $1^{\circ} \times 1^{\circ}$ OMI water vapor VCDs derived from our standard retrieval for January and July 2006. For easy comparison with the MODIS near-IR total water vapor column in the second row, we have converted the OMI VCDs into precipitable water $(\mathrm{cm})$ and indicated both units on the color bars. The third row shows the OMI-MODIS difference maps.

difference panels are shown in the bottom row of Fig. 8. The difference over the ocean is larger than that over the land. Since MODIS data are most useful over the land, we will focus on the land for subsequent comparison.

The joint probability density distributions of MODIS versus OMI data over land for January and July 2006 are shown in the top row of Fig. 9. We have also indicated the regression lines (solid) and 1:1 lines (dashed) in the plot. The linear correlation coefficients are 0.97 and 0.93 for January and July, respectively. For January 2006, the mean of OMIMODIS is $-0.06 \mathrm{~cm}$ and the standard deviation is $0.36 \mathrm{~cm}$. For July 2006, the mean of OMI-MODIS is $-0.18 \mathrm{~cm}$ and the standard deviation is $0.50 \mathrm{~cm}$. Figure 9 shows that the range of the data expands, and the mean of the data shifts to higher values from January to July. More than $80 \%$ of the data over land have water vapor less than $3 \mathrm{~cm}$. For this subset, the average of OMI is lower than that of MODIS by $0.05 \mathrm{~cm}$ in January and by $0.21 \mathrm{~cm}$ in July. For the
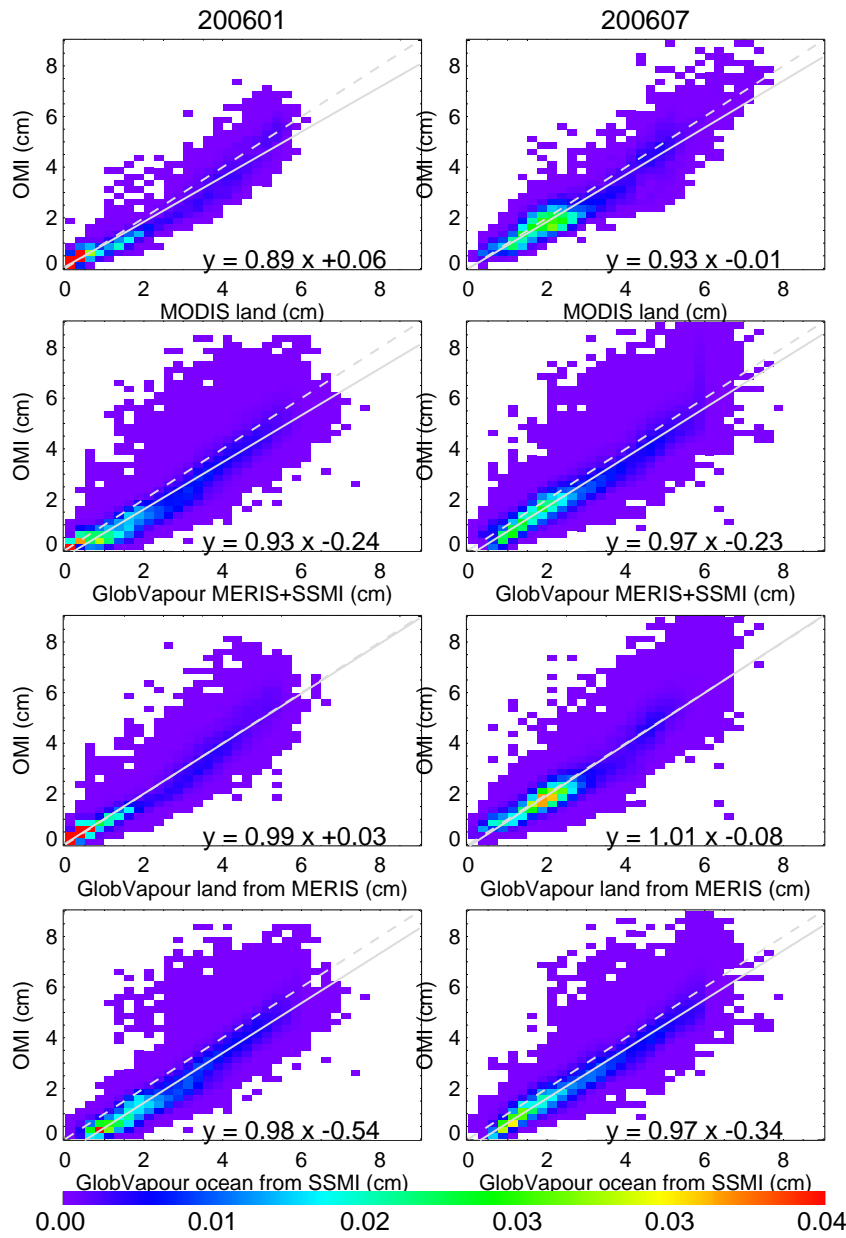

Figure 9. The joint probability density distribution (color), linear regression line (solid) and 1:1 line (dashed) for OMI versus (first row) MODIS over land, (second row) GlobVapour combined MERIS+SSM/I over the globe, (third row) GlobVapour MERIS over land and (fourth row) GlobVapour SSM/I over ocean for (left) January and (right) July 2006. The equation corresponding to the regression line is indicated in each panel.

complementary subset of water vapor greater than $3 \mathrm{~cm}$, the mean of OMI is lower than that of MODIS by $0.16 \mathrm{~cm}$ in January and by $0.08 \mathrm{~cm}$ in July.

The GlobVapour project supported by the European Space Agency (ESA) Data User Element (DUE) program has generated a combined data product from MERIS and SSM/I for 2003-2008 (www.globvapour.info). This product is for observations made over land with MERIS at about 10 a.m. and over ocean with SSM/I at about 6 to 7 a.m. The combination of the two makes an easy-to-use validated global data set of more uniform quality. In Fig. 10, we compare our OMI results with the monthly mean $0.5^{\circ} \times 0.5^{\circ}$ GlobVapour combined MERIS+SSM/I data for January and July of 2006. The gridded OMI data are generated with the same procedure as before but for $0.5^{\circ}$ resolution. The spatial coverage of GlobVapour is much better than that for MODIS. OMI results 


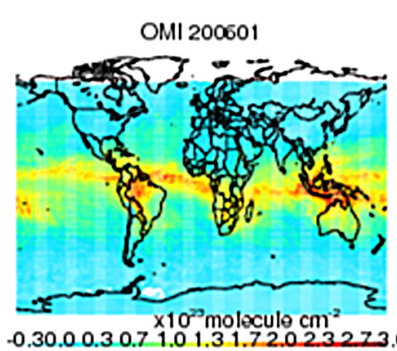

$-0.30 .00 .30 .71 .01 .31 .72 .023273 .0 \cdot 0.30 .00 .30 .71 .01 .31 .72 .023273 .0$ $-1.00 .01 .02 .03 .04 .05 .06 .07 .08 .09 .0-1.00 .01 .02 .03 .04 .05 .06 .07 .08 .09 .00$
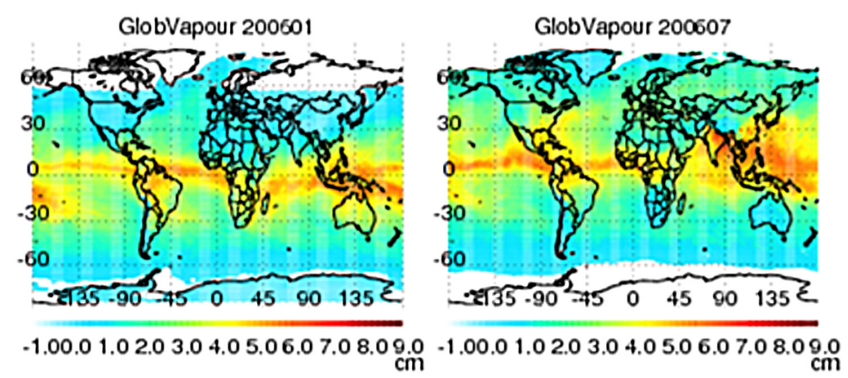

$-1.00 .01 .02 .03 .04 .05 .06 .07 .08 .09 .0$

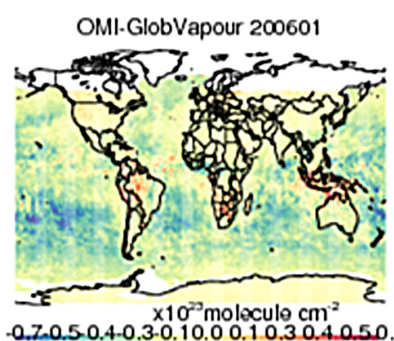

$-0.7-0.5-0.4-0.3-0.10 .00 .10 .30 .4-0.50 .7$

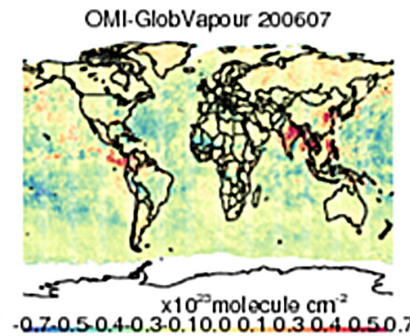

cm
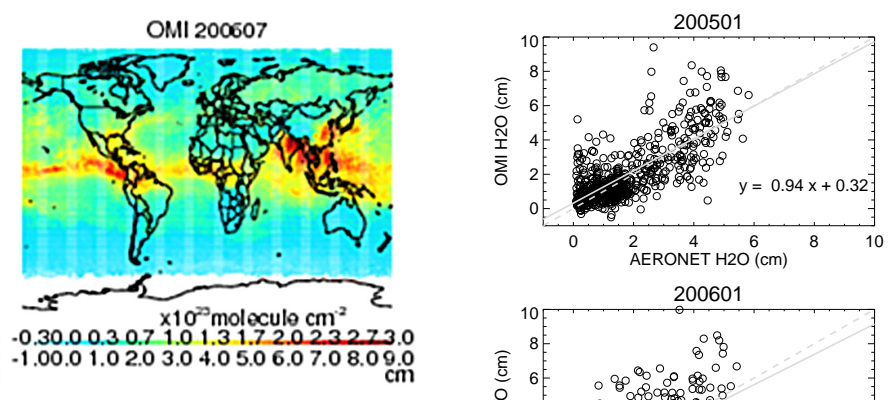

200601
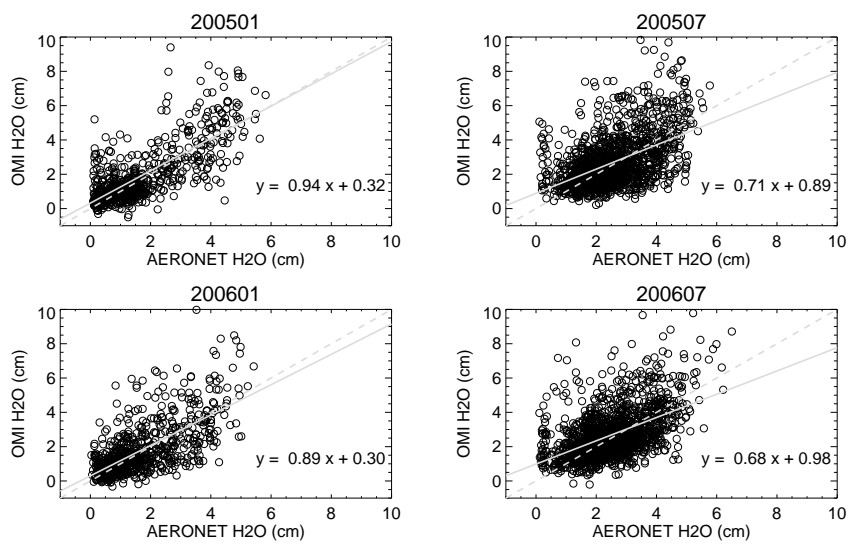

200607

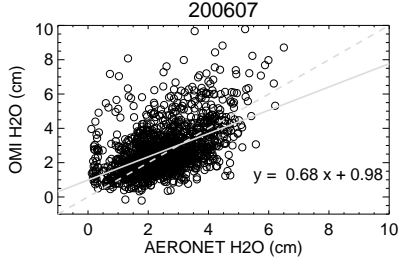

Figure 11. Scatterplots of OMI versus AERONET total precipitable water for (top left) January 2005 (top right) July 2005 (bottom left) January 2006 and (bottom right) July 2006. The regression line corresponding to the equation in each panel is shown as the gray solid line. The $1: 1$ line is shown as the gray dashed line.

correlation coefficients are 0.95 for January and 0.96 for July. The mean of the OMI-SSM/I difference is $-0.58 \mathrm{~cm}$ in January and $-0.41 \mathrm{~cm}$ in July, with a standard deviation of $0.47 \mathrm{~cm}$ and $0.45 \mathrm{~cm}$, respectively.

AERONET is a network of globally distributed groundbased visible and near-IR sun photometers that measure atmospheric aerosol properties, inversion products, and precipitable water (aeronet.gsfc.nasa.gov) (Holben et al., 1998). Total water vapor column is retrieved from the $935 \mathrm{~nm}$ channel. The data used in this study are Version 2 daily averages. They are pre- and post-field calibrated, automatically cloud cleared and manually inspected.

Figure 11 shows the scatterplots of nearly coincident OMI and AERONET precipitable water for January and July in 2005 and 2006. All valid AERONET observations for the month are included for each panel. To find the nearly coincident observations, we use the OMI retrievals that have cloud fraction of $<0.25$ and are within a $0.5^{\circ}$ radius of the AERONET site on the same day. There are typically 1-6 OMI data points for each AERONET data point, and they are averaged for comparison. Since artificial stripes in OMI swaths (Fig. 2) can significantly influence the comparison in this case, we perform an additional post-processing on OMI SCDs to remove the stripes by dividing a normalization vector. The normalization vector is derived using the mean of the middle third of the monthly averaged swaths and normalized so that the mean of the vector is unity. The de-striped SCDs are divided by the AMFs to convert to VCDs before subsequent processing. The correlation coefficients are in the range of 0.49 to 0.75 . There appears to be better agreement in January than in July for both years. The slopes of the AERONET vs. OMI regression lines are $<1$. Considering that coincident OMI results have much larger uncertainty here than in Figs. 8-10 due to far fewer data points available 

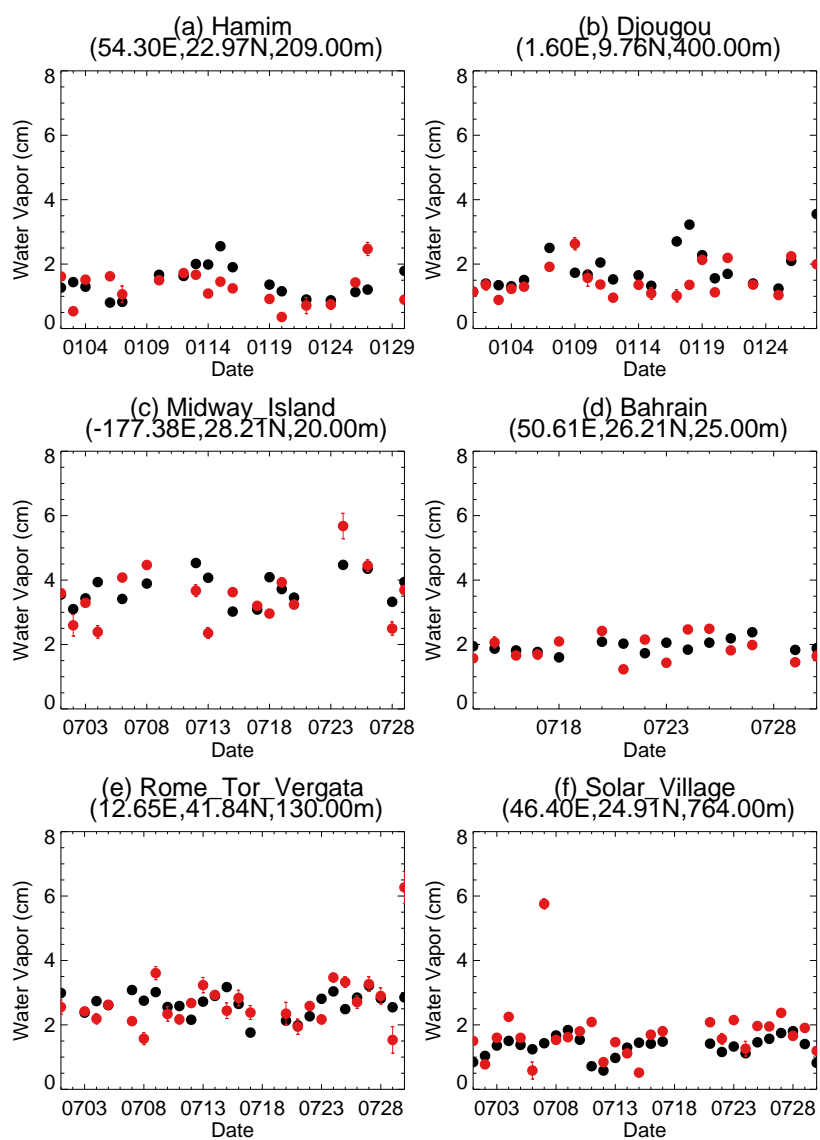

Figure 12. Time-series comparison between (black) AERONET and (red) OMI total precipitable water (cm) at selected sites in 2006. Dates on the horizontal axis are month followed by day.

for averaging, in addition to the different observational footprint and the highly variable nature of water vapor, the degree of agreement indicates that water vapor retrieval using OMI visible spectra is promising.

Figure 12 shows time-series comparisons between daily AERONET and OMI precipitable water for selected sites. This figure shows comparison not only of the mean but also of the day-to-day variation. The error bar for OMI in this plot only includes the uncertainty of the average of OMI SCDs. Other sources of error, including the error of AMF, the mismatch in timing between OMI and AERONET observation, the difference in observational footprint size, the spread due to scene inhomogeneity and the imperfection of the destripping procedure, are not included. Consequently, the total error for OMI should be larger than that shown in the figure. Despite this, we have found reasonably good matches between the two data sets. In the examples shown, the OMI result tracks both the mean and the variation of the AERONET result well except for occasional outliers. It is not surprising that we have also found examples where OMI does not agree with AERONET (not shown) due to the multiple error sources mentioned above. A comprehensive error analysis and data validation will be performed later.

\section{Summary}

Water vapor is an important molecule for weather, climate and atmospheric chemistry. There are distinct water vapor features in the OMI visible spectra that can be exploited to retrieve water vapor column amounts.

In this paper, we have presented our two-step operational OMI water vapor retrieval algorithm. We perform direct spectral fitting in the optimized spectral region of 430 $480 \mathrm{~nm}$ to retrieve water vapor slant column density. This $50 \mathrm{~nm}$ long window includes the water vapor absorption feature at about $442 \mathrm{~nm}$ and $470 \mathrm{~nm}$. Besides water vapor, we also fit $\mathrm{O}_{3}, \mathrm{O}_{2}-\mathrm{O}_{2}, \mathrm{NO}_{2}$, liquid water, the ring effect, the water ring effect and third-order closure polynomials. Our median retrieval uncertainty is about $1.2 \times 10^{23}$ molecule $\mathrm{cm}^{-2}$, about $50 \%$ smaller than that obtained when using a shorter retrieval window. We have examined the sensitivity of our SCDs to the retrieval window, interfering molecules, reference spectra and other factors. Results show that it is important to include liquid water in our standard retrieval and use a relatively long retrieval window to reduce uncertainty. Results also show that the common mode over the ocean still has apparent structures as compared with that over the land, indicating the importance of improving the liquid water spectroscopy in this wavelength range.

We convert SCD to VCD by dividing by the AMF, which is a function of the scattering weight and shape factor. In our operational retrieval, we use a pre-calculated look-up table for the scattering weight and monthly mean assimilated water vapor profiles for the shape factor. We investigate the sensitivity of AMF to wavelength, solar zenith angle, surface albedo and cloud height. Results show that surface albedo and cloud information can lead to significant errors in AMF and therefore VCD. Our Level 2 product contains both scattering weights and AMFs in addition to VCDs for evaluation with and assimilation into models.

We compare our results with the MODIS near-IR data, GlobVapour combined MERIS+SSM/I product and AERONET measurements. Results show general agreement in terms of the spatial and temporal distribution both at the global level and for many sites. Future work will concentrate on further refining the retrieval algorithm, maintaining its long-term stability and performing extensive error analysis and data validation.

Acknowledgements. This study is supported by NASA's Atmospheric Composition: Aura Science Team program under grant NNX11AE58G and the Smithsonian Institution. We acknowledge the OMI International Science Team for providing OMI data used in this study, the MODIS team for providing MODIS water vapor data, and the GlobVapour project for providing the combined MERIS+SSM/I water vapor product. We thank the AERONET project for its effort in establishing and maintaining measurement sites. We thank R. Lang and an anonymous reviewer for their reviews. We thank R. Lindstrot for providing comments. 
Edited by: M. Weber

\section{References}

Acarreta, J. R., De Haan, J. F., and Stammes, P.: Cloud pressure retrieval using the $\mathrm{O}_{2}-\mathrm{O}_{2}$ absorption band at $477 \mathrm{~nm}$, J. Geophys. Res., 109, D05204, doi:10.1029/2003JD003915, 2004.

Aliwell, S. R., Van Roozendael, M., Johnston, P. V., Richter, A., Wagner, T., Ariander, D. W., Burrows, J. P., Fish, D. J., Jones, R. L., Tornkvist, K. K., Lambert, J. C., Pfeilsticker, K., and Pundt, I.: Analysis for $\mathrm{BrO}$ in zenith-sky spectra: An intercomparison exercise for analysis improvement, J. Geophys. Res.-Atmos., 107, 4199, doi:10.1029/2001JD000329, 2002.

Aumann, H. H., Chahine, M. T., Gautier, C., Goldberg, M. D., Kalnay, E., McMillin, L. M., Revercomb, H., Rosenkranz, P. W., Smith, W. L., Staelin, D. H., Strow, L. L., and Susskind, J.: AIRS/AMSU/HSB on the Aqua mission: design, science objectives, data products, and processing systems, IEEE T. Geosci. Remote, 41, 253-264, 2003.

Boukabara, S. A., Garrett, K., and Chen, W. C.: Global coverage of total precipitable water using a microwave variational algorithm, IEEE T. Geosci. Remote, 48, 3608-3621, doi:10.1109/TGRS.2010.2048035, 2010.

Brion, J., Chakir, A., Daumont, D., Malicet, J., and Parisse, C.: High-resolution laboratory absorption cross-section of $\mathrm{O}_{3}$ - temperature effect, Chem. Phys. Lett., 213, 610-612, doi:10.1016/0009-2614(93)89169-I, 1993.

Caspar, C. and Chance, K. V.: GOME wavelength calibration using solar and atmospheric spectra, in: Third ERS Symposium on Space at the Service of our Environment, edited by: Guyenne, T. D. and Danesy, D., vol. 414 of ESA Special Publication, 609 pp., 1997.

Chance, K. V.: Analysis of BrO measurements from the Global Ozone Monitoring Experiment, Geophys. Res. Lett., 25, 33353338, 1998.

Chance, K. V. and Kurucz, R. L.: An improved high-resolution solar reference spectrum for Erath's atmosphere measurements in the ultraviolet, visible, and near infrared, J. Quant. Spectr. Radiat. Tran., 111, 1289-1295, doi:10.1016/j.jqsrt.2010.01.036, 2010.

Chance, K. V. and Spurr, R. J. D.: Ring effect studies: Rayleigh scattering, including molecular parameters for rotational Raman scattering, and the Fraunhofer spectrum, Appl. Optics, 36, 52245230, 1997.

Chance, K. V., Kurosu, T. P., and Sioris, C. E.: Undersampling correction for array detector based satellite spectrometers, Appl. Optics, 44, 1296-1304, 2005.

Dirksen, R., Dobber, M., Voors, R., and Levelt, P.: Prelaunch characterization of the Ozone Monitoring Instrument transfer function in the spectral domain, Appl. Optics, 45, 3972-3981, 2006.

Eskes, H. J. and Boersma, K. F.: Averaging kernels for DOAS totalcolumn satellite retrievals, Atmos. Chem. Phys., 3, 1285-1291, doi:10.5194/acp-3-1285-2003, 2003.

Ferraro, R. R., Weng, F. Z., Grody, N. C., Zhao, L. M., Meng, H., Kongoli, C., Pellegrino, P., Qiu, S., and Dean, C.: NOAA operational hydrological products derived from the advanced microwave sounding unit, IEEE T. Geosci. Remote, 43, 1036-1049, doi:10.1109/TGRS.2004.843249, 2005.
Gao, B. and Kaufman, Y. J.: Water vapor retrievals using Moderate Resolution Imaging Spectroradiometer (MODIS) near-infrared channels, J. Geophys. Res., 108, 4389, doi:10.1029/2002JD003023, 2003.

González Abad, G., Liu, X., Chance, K., Wang, H., Kurosu, T. P., and Suleiman, R.: Updated SAO OMI formaldehyde retrieval, Atmos. Meas. Tech. Discuss., 7, 1-31, doi:10.5194/amtd-7-12014, 2014.

Grossi, M., Valks, P., Loyola, D., Aberle, B., Slijkhuis, S., Wagner, T., Beirle, S., and Lang, R.: Total column water vapour measurements from GOME-2 MetOp-A and MetOp-B, Atmos. Meas. Tech. Discuss., 7, 3021-3073, doi:10.5194/amtd-7-3021-2014, 2014.

Holben, B. N., Eck, T. F., Slutsker, I., Tanré, D., Buis, J. P., Setzer, A., Vermote, E., Reagan, J. A., Kaufman, Y., Nakajima, T., Lavenu, F., Jankowiak, I., and Smirnov, A.: AERONET - a federated instrument network and data archive for aerosol characterization, Remote Sens. Environ., 66, 1-16, 1998.

Joiner, J. and Vassilkov, A. P.: First results from the OMI rotational Raman scattering cloud pressure algorithm, IEEE Trans. Geosci Remote Sens., 44, 1272-1282, 2006.

King, M., Menzel, W. P., Kaufman, Y. J., Tanre, D., Gao, B. C., Plantnick, S., Ackerman, S. A., Remer, L. A., Pincus, R., and Hubanks, P. A.: Cloud and aerosol properties, precipitable water, and profiles of temperature and water vapor from MODIS, IEEE T. Geosci. Remote, 41, 442-458, doi:10.1109/TGRS.2002.808226, 2003.

Kleipool, Q. L., Dobber, M. R., De Haan, J. F., and Levelt, P. F.: Earth surface reflectance climatology from three years of OMI data. J. Geophys. Res., 113, D18308, doi:10.1029/2008JD010290, 2008.

Koelemeijer, R. B. A., De Hann, J. F., and Stammes, P.: A database of spectral surface reflectivity in the range $335-772 \mathrm{~nm}$ derived from 5.5 years of GOME observations. J. Geophys. Res., 108, D24070, doi:10.1029/2002JD002429, 2003.

Lee, S., Kouba, J., Schutz, B., Kim, D. H., and Lee, Y. J.: Monitoring precipitable water vapor in real-time using global navigation satellite systems, J. Geodesy, 87, 923-934, doi:10.1007/s00190013-0655-y, 2013.

Levelt, P. F., van den Oord, G. H. J., Dobber, M. R., Malkki, A., Visser, H., de Vries, J., Stammes, P., Lundell, J. O. V., and Saari, H.: The Ozone Monitoring Instrument, IEEE T. Geosci. Remote, 44, 1093-1101, 2006.

Lindström, P. and Wedin, P.-Å.: Methods and software for nonlinear least squares problems, Technical Report UMINF-133.87, Institute of Information Processing, University of Umeå, Umeå, Sweden, 1988.

Lindstrot, R., Preusker, R., Diedrich, H., Doppler, L., Bennartz, R., and Fischer, J.: 1D-Var retrieval of daytime total columnar water vapour from MERIS measurements, Atmos. Meas. Tech., 5, 631646, doi:10.5194/amt-5-631-2012, 2012.

Martin, R. V., Chance, K., Jacob, D. J., Kurosu, T. P., Spurr, R. J. D., Bucsela, E., Gleason, J. F., Palmer, P. I., Bey, I., Fiore, A. M., Li, Q., Yantosca, R. M., and Koelemeijer, R. B. A.: An improved retrieval of tropospheric nitrogen dioxide from GOME, J. Geophys. Res., 107, 4437, doi:10.1029/2001JD001027, 2002.

Noël, S., Buchwitz, M., Bovensmann, H., and Burrows, J. P.: Retrieval of total water vapor column amounts from GOME/ERS-2 data, Adv. Space Res., 29, 1697-1702, 2002. 
Noël, S., Buchwitz, M., and Burrows, J. P.: First retrieval of global water vapour column amounts from SCIAMACHY measurements, Atmos. Chem. Phys., 4, 111-125, doi:10.5194/acp-4-1112004, 2004.

Palmer, P. I., Jacob, D. J., Chance, K. V., Martin, R. V., Spurr, R. J. D., Kurosu, T. P., Bey, I., Yantosca, R., Fiore, A., and Li, Q.: Air mass factor formulation for spectroscopic measurements from satellites: application to formaldehyde retrievals from the Global Ozone Monitoring Experiment, J. Geophys. Res., 106, 1453914550, doi:10.1029/2000JD900772, 2001.

Pope, R. M. and Fry, E. S.: Absorption spectrum (380-700 nm) of pure water. 2. Integrating cavity measurements, Appl. Optics, 36, 8710-8723, doi:10.1364/AO.36.008710, 1997.

Rothman, L. S., Gordon, I. E., Barbe, A., Benner, D. C., Bernath, P. F., Birk, M., Boudon, V., Brown, L. R., Campargue, A., Champion, J.-P., Chance, K., Coudert, L. H., Dana, V., Devi, V. M., Fally, S., Flaud, J. M., Gamache, R. R., Goldman, A., Jacquemart, D., Lacome, N., Lafferty, W. J., Mandin, J. Y., Massie, S. T., Mikhailenko, S. N., Miller, C. E., Moazzen-Ahmadi, N., Naumenko, O. V., Nikitin, A. V., Orphal, J., Perevalov, V. I., Perrin, A., Predoi-Cross, A., Rinsland, C. P., Rotger, M., Simeckova, M., Smith, M. A. H., Sung, K., Tashkun, S. A., Tennyson, J., Toth, R. A., Vandaele, A. C., and Vander Auwera, J.: The HITRAN 2008 molecular spectroscopic database, J. Quant. Spectr. Radiat. Tran., 110, 533-572, 2009.

Rothman, L. S., Gordon, I. E., Babikov, Y., Barbe, A., Benner, D. C., Bernath, P. F., Birk, M., Bizzocchi, L., Boudon, V., Brown, L. R., Campargue, A., Chance, K., Cohen, E. A., Coudert, L. H., Devi, V. M., Drouin, B. J., Fayt, A., Flaud, J. M., Gamache, R. R., Harrison, J. J., Hartmann, J. M., Hill, C., Hodges, J. T., Jacquemart, D., Jolly, A., Lamouroux, J., Le Roy, R. J., Li, G., Long, D. A., Lyulin, O. M., Mackie, 5 C. J., Massie, S. T., Mikhailenko, S., Muller, H. S. P., Naumenko, O. V., Nikitin, A. V., Orphal, J., Perevalov, V., Perrin, A., Polovtseva, E. R., Richard, C., Smith, M. A. H., Starikova, E., Sung, K., Tashkun, S., Tennyson, J., Toon, G. C., Tyuterev, V. G., and Wagner, G.: The HITRAN 2012 molecular spectroscopic database, J. Quant. Spectr. Radiat. Tran., 130, 4-50, 2013.

Schneider, M. and Hase, F.: Optimal estimation of tropospheric $\mathrm{H}_{2} \mathrm{O}$ and $\delta \mathrm{D}$ with IASI/METOP, Atmos. Chem. Phys., 11, 11207-11220, doi:10.5194/acp-11-11207-2011, 2011.

Schoeberl, M. R., Douglass, A. R., Hilsenrath, E., Bhartia, P. K., Beer, R., Waters, J. W., Gunson, M. R., Froidevaux, L., Gille, J. C., Barnett, J. J., Levelt, P. F., and de Cola, P.: Overview of the EOS Aura mission, IEEE T. Geosci. Remote, 44, 1066-1074, 2006.

Sneep, M., de Haan, J. F., Stammes, P., Wang, P., Vanbauce, C., Joiner, J., Vasilkov, A. P., and Levelt, P. F.: Three-way comparison between OMI and PARASOL cloud pressure products, J. Geophys. Res., 113, D15S23, doi:10.1029/2007JD008694, 2008.

Spurr, R. J. D.: VLIDORT: a linearized pseudo-spherical vector discrete ordinate radiative transfer code for forward model and retrieval studies in multilayer multiple scattering media, J. Quant. Spectr. Radiat. Tran., 102, 316-342, doi:10.1016/j.jqsrt.2006.05.005, 2006.
Stammes, P. and Noordhoek, R.: OMI Algorithm Theoretical Basis Document, vol. III, Clouds, aerosols, and surface UV irradiance, ATBD-OMI-03, Version 2.0, August, 2002.

Stammes, P., Sneep, M., de Haan, J. F., Veefkind, J. P., Wang, P., and Levelt, P. F.: Effective cloud fractions from the Ozone Monitoring Instrument: theoretical framework and validation, J. Geophys. Res., 113, D16S38, doi:10.1029/2007JD008820, 2008.

Thalman, R. and Volkamer, R.: Temperature dependent absorption cross-sections of $\mathrm{O}_{2}-\mathrm{O}_{2}$ collision pairs between 340 and $630 \mathrm{~nm}$ and at atmospherically relevant pressure, Phys. Chem. Chem. Phys., 15, 15371-15381, doi:10.1039/c3cp50968k, 2013.

Vandaele, A. C., Hermans, C., Simon, P. C., Carleer, M., Colin, R., Fally, S., Merienne, M. F., Jenouvrier, A., and Coquart, B.: Measurements of the $\mathrm{NO}_{2}$ absorption cross-section from $42000 \mathrm{~cm}(-$ 1) to $10000 \mathrm{~cm}(-1)(238-1000 \mathrm{~nm})$ at $220 \mathrm{~K}$ and $294 \mathrm{~K}$, J. Quant. Spectr. Radiat. Trans., 59, 171-184, doi:10.1016/S00224073(97)00168-4, 1998.

Vasilkov, A., Joiner, J., Spurr, R., Bhartia, P. K., Levelt, P., and Stephens, G.: Evaluation of the OMI cloud pressures derived from rotational Raman scattering by comparisons with other satellite data and radiative transfer simulations, J. Geophys. Res., 113, D15S19, doi:10.1029/2007JD008689, 2008.

Veihelmann, B. and Kleipool, Q.: Reducing along-track stripes in OMI-Level 2 products, available at: http: //disc.sci.gsfc.nasa.gov/Aura/dataholdings/OMI/documents/ v003/RD08_TN785_i1_Reducing_AlongTrack_Stripes.pdf (last access: 17 January 2014), 2006.

Volkamer, R., Spietz, P., Burrows, J., and Platt, U.: Highresolution absorption cross-section of glyoxal in the UV/vis and IR spectral ranges, J. Photochem. Photobio., 172, 35-46, doi:10.1016/j.jphotochem.2004.11.011, 2005.

Wagner, T., Heland, J., Zöger, M., and Platt, U.: A fast $\mathrm{H} 2 \mathrm{O}$ total column density product from GOME - Validation with insitu aircraft measurements, Atmos. Chem. Phys., 3, 651-663, doi:10.5194/acp-3-651-2003, 2003.

Wagner, T., Beirle, S., Sihler, H., and Mies, K.: A feasibility study for the retrieval of the total column precipitable water vapour from satellite observations in the blue spectral range, Atmos. Meas. Tech., 6, 2593-2605, doi:10.5194/amt-6-2593-2013, 2013.

Wang, J., Zhang, L., Dai, A., Van Hove, T., and Van Baelen J.: A nearly global, 2-hourly data set of atmospheric precipitable water from ground-based GPS measurements, J. Geophys. Res., 112, D11107, doi:10.1029/2006JD007529, 2007.

Worden, J., Kulawik, S., Frankenberg, C., Payne, V., Bowman, K., Cady-Peirara, K., Wecht, K., Lee, J.-E., and Noone, D.: Profiles of $\mathrm{CH}_{4}, \mathrm{HDO}, \mathrm{H}_{2} \mathrm{O}$, and $\mathrm{N}_{2} \mathrm{O}$ with improved lower tropospheric vertical resolution from Aura TES radiances, Atmos. Meas. Tech., 5, 397-411, doi:10.5194/amt-5-397-2012, 2012. 